\title{
Sobre a Relação entre Filogenia e Ontogenia no Desenvolvimento da Lateralidade na Infância
}

\author{
The Relationship between Phylogeny and Ontogeny \\ in the Development of Infant Laterality
}

\author{
Rosana Machado de Souza*,a \& Luis Augusto Teixeira ${ }^{b}$ \\ ${ }^{a}$ Universidade Federal de São Carlos, São Carlos, Brasil \& ${ }^{b}$ Universidade de São Paulo, São Paulo, Brasil
}

\begin{abstract}
Resumo
A lateralidade humana tem sido concebida como sendo predominantemente o resultado de fatores filogenéticos do desenvolvimento humano, enquanto que apenas importância secundária tem sido atribuída à interação indivíduo-ambiente. Neste estudo é apresentada uma revisão crítica da literatura com indicadores da influência de fatores filo e ontogenéticos no desenvolvimento da lateralidade, com particular ênfase aos primeiros anos de vida. A partir dos resultados discutidos, propomos que a lateralidade humana é um processo dinâmico, com efeitos marcantes das experiências sensório-motoras lateralizadas sobre a preferência manual e assimetrias interlaterais de desempenho motor.

Palavras-chave: Dominância lateral; Manualidade; Filogênese; Ontogênese.
\end{abstract}

\begin{abstract}
Human laterality has been conceived as resulting, predominantly, from phylogenetic factors in human development, whereas individual-environment interaction is thought to play only a minor role. This study aims at presenting a critical review of literature showing evidence of the effect of phylogenetic and ontogenetic factors on the development of laterality, with particular emphasis on the first years of life. From the results presented, we propose that human laterality is a dynamic process, with sharp effects of lateralized sensorimotor experiences over manual preference and interlateral asymmetry of motor performance. Keywords: Lateral dominance; Handedness; Phylogenesis; Ontogenesis.
\end{abstract}

$\mathrm{Na}$ teorização sobre origem e desenvolvimento da lateralidade humana dois pontos de vista antagônicos têm sido defendidos. A visão predominante é de que a lateralidade é essencialmente determinada por fatores filogenéticos (cf. Annett, 1978, 1996, 1999; M. P. Bryden, 1990; Levy, 1976). Por esta concepção, a preferência manual é derivada de uma assimetria interlateral, originária da maior capacidade de controle motor com a mão preferida em comparação com a mão não-preferida. Oferece-se como explanação para as assimetrias interlaterais de desempenho a concepção de que os genes trazem embutidas em seu código especificações sobre o desenvolvimento diferenciado dos hemisférios cerebrais, determinando qual deles será o hemisfério dominante em relação a determinadas fun-

\footnotetext{
* Endereço para correspondência: Laboratório Sistemas Motores Humanos, Escola de Educação Física e Esporte, USP, SP. CEP 05508-030. Tel.: (11) 3091-8795. E-mail: romasouza@yahoo.com.br

Os autores agradecem à Fundação de Amparo à Pesquisa do Estado de São Paulo (FAPESP) pela bolsa de estudos concedida ao primeiro autor (\#2008/02145-8) e ao Conselho Nacional de Desenvolvimento Científico e Tecnológico $(\mathrm{CNPq})$ pela bolsa produtividade concedida ao segundo autor (\#308312/2006-6).
}

ções. Assim, considera-se que para pessoas destras o hemisfério cerebral direito seja o principal responsável por processamento paralelo e percepção de aspectos espaciais do ambiente, enquanto que o hemisfério esquerdo desempenha o papel principal no sequenciamento e temporização de movimentos (Goodale, 1990). Uma vez que o controle corporal pelo córtex cerebral é predominantemente cruzado, o lado corporal contrário ao hemisfério cerebral dominante tem maior potencial de controle do que o lado corporal ipsilateral. A partir de tais princípios, seria de se esperar uma vantagem generalizada e consistente de desempenho em tarefas motoras realizadas com o lado dominante em relação ao desempenho com o lado não-dominante, havendo relativa independência de fatores ambientais.

Uma concepção antagônica foi formulada originalmente por Provins (1997a, 1997b), na qual é proposto que o componente ontogenético, dado pelas experiências lateralizadas com os segmentos corporais ao longo da vida, constitui o fator principal na formação da lateralidade humana. Uma das idéias centrais dessa proposição é de que o potencial de aprendizagem com os lados direito e esquerdo do corpo é equivalente. Assim, a vantagem de desempenho com um dado segmento corporal em relação ao segmento contralateral homólogo seria devida ao 
diferencial de prática entre ambos os segmentos ao invés de ser resultante de uma capacidade superior de um dos hemisférios cerebrais para controle e aprendizagem de ações motoras. A partir dessa perspectiva, tanto preferências manuais quanto assimetrias interlaterais de desempenho seriam moldadas por experiências sensoriais e motoras lateralizadas acumuladas durante o ciclo de vida.

O presente trabalho tem como propósito fazer uma revisão de literatura dos achados de pesquisa relacionados ao debate sobre a participação de fatores filogenéticos e ontogenéticos na formação da lateralidade humana, com particular interesse em estudos com bebês. A este respeito, a racionalidade subjacente à interpretação dos resultados é de que quanto mais precocemente forem observados comportamentos lateralizados nos bebês menor a chance de haver influência de fatores ambientais nas observações. Preferências laterais e assimetrias de desempenho motor no início do processo de desenvolvimento infantil poderiam indicar, assim, mais claramente a ação genotípica sobre a formação da lateralidade humana. Por outro lado, modificações da relação de preferência/desempenho entre os lados do corpo como consequência de experiências práticas, durante a aquisição de comportamento motor habilidoso, são indicativas do papel de fatores ontogenéticos no desenvolvimento da lateralidade.

\section{Suporte à Participação Filogenética na Formação da Lateralidade}

A maioria dos indivíduos adultos da espécie humana apresentam preferência manual direita, a qual tem sido relatada desde os primeiros dias de vida (Cioni \& Pellegrinetti, 1982) até idades mais avançadas (Porac, Coren, \& Duncan, 1980; Teixeira, 2008). Além disso, tal predomínio de preferência manual direita tem sido observado nas mais variadas comunidades e culturas (cf. M. P. Bryden, Ardila, \& Ardila, 1993; Dahmen \& Fagard, 2005; Dittmar, 2002; Provins, 1990; Singh, Manjary, \& Dellatolas, 2001). Essas observações têm conduzido à concepção de que os humanos estão programados por natureza para ser destros. Canhotos com certa frequência têm sido considerados como resultado de problemas ao nascimento, tais como falta de oxigênio, ou desordens no funcionamento do sistema nervoso, como em casos de dislexia e esquizofrenia (Saugstad, 1998). Particularmente durante o desenvolvimento infantil, têm sido observados comportamentos precocemente lateralizados. Estudos com fetos e neonatos evidenciam o estabelecimento precoce de preferência pelo uso de uma das mãos (de Vries et al., 2001; Michel \& Harkins, 1986; Michel, Ovrut, \& Harkins, 1985; Rönnqvist \& Domellof, 2006) e a manifestação de características comportamentais que denotam desempenho mais refinado com um lado do corpo em comparação com o lado contrário (Caplan \& Kinsbourne, 1976; Domellöf, Rönnqvist, \& Hopkins, 2007; Nagy et al., 2005). Essas evidências têm sido interpretadas como indício de que assimetrias estruturais na arquitetura dos hemisférios cerebrais estão na raiz do desenvolvimento da lateralidade humana.

Uma das principais proposições teóricas de que fatores genéticos correspondem ao elemento determinante na formação da lateralidade humana foi formulada por Annett (1978), a qual está fundamentada em três princípios. Primeiro, padrões de preferência manual nos animais em geral dependem de uma distribuição aproximadamente normal de assimetrias inter-hemisféricas, determinando diferenças de desempenho entre as mãos/ patas direita e esquerda. Isso implica que a preferência manual não é uma variável discreta, mas uma variável contínua que pode ser expressa em uma variedade de frequências. O segundo princípio é de que a distribuição contínua de assimetrias interlaterais depende de diferenças aleatórias entre os lados direito e esquerdo do corpo, originando-se acidentalmente durante fases precoces do desenvolvimento. $\mathrm{O}$ terceiro princípio postula que em seres humanos, em particular, a distribuição de assimetrias entre os lados do corpo é deslocada à direita como consequência da ação de um gene determinando a assimetria inter-hemisférios cerebrais. Este gene, hipoteticamente, promove a dominância do hemisfério cerebral esquerdo sobre o hemisfério direito para funções associadas ao controle motor e faz parte do genoma da grande maioria dos seres humanos. Em decorrência de tal assimetria estrutural entre os dois hemisférios cerebrais, o controle com o lado direito do corpo seria favorecido em comparação com o lado esquerdo. A preferência pelo lado direito do corpo, por esta proposição, seria estabelecida como subproduto da vantagem inata de controle de movimentos voluntários ao invés de ser determinada diretamente pelo código genético. Nos casos em que o gene de dominância direita está ausente, por outro lado, não haveria influência de fatores genéticos sobre a formação da lateralidade. Assim, as assimetrias interlaterais de desempenho em indivíduos desprovidos do gene de dominância direita seriam desenvolvidas de forma aleatória, por meio de influências ambientais durante o processo de desenvolvimento. Nestes casos, então, os indivíduos desenvolveriam sua preferência lateral ao acaso. A dominância direita na maioria dos indivíduos, por esta proposição, seria afetada apenas de forma superficial por fatores ambientais, sendo hipoteticamente responsável pela variabilidade na magnitude de preferências manuais na população. Consequentemente, fatores ontogenéticos desempenhariam apenas um papel secundário na prevalência de indivíduos com preferência manual direita entre os humanos (cf. McManus, 1985; Yeo, Gangestad, \& Daniel, 1993, para modelos genéticos de lateralidade alternativos).

Uma proposição adicional associada à noção do caráter filogenético da dominância manual é a hipótese de dominância dinâmica (Sainburg, 2002). Segundo esta 
hipótese, a vantagem favorável ao lado dominante é devida ao melhor controle da dinâmica dos movimentos, levando a movimentos mais retilíneos em ações de alcançar um alvo, por exemplo, em relação ao lado contrário do corpo. Como este melhor controle da dinâmica de movimentos em ações orientadas a alvos espaciais tem sido consistentemente observado em indivíduos com preferência manual direita (Bagesteiro \& Sainburg, 2002; Sainburg, 2002; Sainburg \& Wang, 2002; Wang \& Sainburg, 2007), seria plausível supor que tal vantagem tenha origem em uma assimetria estrutural na arquitetura neural dos hemisférios cerebrais. Tal proposta está em consonância com o modelo conceitual apresentado por Annett (1978).

Como esperado pela proposição filogenética, uma série de estudos têm apontado uma tendência geral de preferência ou assimetria motora favorável ao lado direito do corpo na infância. Algumas das exibições mais precoces desse comportamento lateralizado foram observadas por Hepper, McCartney e Shannon (1998) em fetos com apenas 10 semanas de idade gestacional. Nesse estudo foram observados os movimentos dos braços direito e esquerdo de 72 fetos, por meio de ultrassonografia. Os resultados indicaram que 63 fetos apresentaram preferência por um dos braços. Uma análise de ações manuais espontâneas indicou que $85 \%$ daqueles demonstrando preferência manual direita no útero exibiram mais movimentos com o braço direito. Na continuação do estudo vários anos depois, Hepper, Wells e Lynch (2005) observaram que aos 10-12 anos de idade de 60 fetos que foram mais ativos com a mão direita no útero todos se tornaram destros, e de 15 fetos mais ativos com a mão esquerda 10 tornaram-se canhotos. Esses estudos sugerem que a preferência manual foi estabelecida em grande parte antes do nascimento, sustentando o ponto de vista de determinância filogenética da lateralidade.

Suporte à noção da existência de uma relação entre dominância hemisférica esquerda para ações manuais e preferência manual direita foi fornecido em um estudo realizado por Strogonova, Pushina, Orekhova, Posikera e Tsetlin (2004). Nesta investigação foram encontradas diferenças na assimetria cerebral entre indivíduos com preferência manual esquerda, direita ou indefinida. O estudo incluiu bebês de 10-11 meses de idade, que foram submetidos a uma avaliação de eletroencefalografia durante a ação de alcançar um objeto. Os resultados revelaram uma ativação mais acentuada do hemisfério cerebral esquerdo nos bebês que apresentaram preferência manual direita na ação analisada, enquanto que os demais bebês apresentaram distribuição funcional mais simétrica entre os hemisférios cerebrais. Como tal assimetria de ativação neural entre os hemisférios cerebrais foi observada precocemente durante o processo de desenvolvimento somente nos bebês com preferência manual direita, este achado oferece suporte à noção de que as relações funcionais entre os hemisférios cerebrais são definidas precocemente durante o desenvolvimento infantil.

Sustentação adicional à perspectiva filogenética tem sido oferecida pela observação de que a preferência de orientação da cabeça em neonatos está correlacionada com a preferência manual de seus pais (Cioni \& Pellegrinetti, 1982; Liederman \& Kinsbourne, 1980; Peters \& Petrie, 1979). Cioni e Pellegrinetti (1982), por exemplo, avaliaram assimetrias laterais em funções motoras e sensoriais em neonatos de 2 a 4 dias de vida. Os bebês foram divididos em dois grupos, de acordo com a preferência manual de seus pais. Um grupo foi composto por neonatos descendentes de pais destros, enquanto que o outro grupo apresentava descendência de pelo menos um dos pais canhoto ou ambidestro. Os resultados indicaram que o grupo cujos pais eram destros demonstrou preferência de rotação da cabeça para o lado direito, enquanto que no outro grupo essa preferência lateral à direita foi observada em menor frequência (ver também Annett, 1978; Caplan \& Kinsbourne, 1976). Evidências adicionais têm indicado que a preferência de orientação da cabeça no neonato é um importante elemento para predição da preferência manual em idades mais avançadas. Coryell e Michel (1978) avaliaram longitudinalmente bebês de uma a 12 semanas após o nascimento. Nesse estudo foram analisadas a preferência lateral de orientação voluntária da cabeça e a frequência de manifestação do reflexo tônico cervical assimétrico para cada lado do corpo, além de movimentos de alcance eliciados pela visão de um dos braços. Os resultados revelaram que $75 \%$ dos bebês demonstraram preferência de orientação da cabeça à direita, enquanto que apenas $13 \%$ demonstraram preferência de orientação da cabeça à esquerda, com os demais não demonstrando preferência lateral. A frequência do reflexo tônico para cada lado do corpo foi altamente correlacionada à orientação voluntária da cabeça. Esse viés de orientação da cabeça à direita foi responsável pela maior frequência de contato visual com a mão direita. Em estudo subsequente, Coryell (1985) avaliou a preferência manual em 8 crianças que haviam participado do estudo de Coryell e Michel (1978), com idades variando entre 3,5 e 6 anos. Os resultados dessa avaliação foram comparados com os resultados preliminares de preferência de orientação da cabeça e visualização da mão. Dentre as crianças avaliadas, 6 desenvolveram preferência manual na direção predita pela preferência de orientação da cabeça. Esses resultados sugerem que a preferência de orientação lateral da cabeça é um fator presente ao nascimento que está associado ao desenvolvimento da preferência manual.

Assimetria interlateral precoce favorável ao lado direito do corpo tem sido observada também em ações de alcançar. Em um estudo realizado com bebês entre 4 e 7 meses de idade, Morange e Bloch (1996) observaram que apesar de objetos dispostos do lado direito ou esquerdo do bebê terem sido alcançados com a mão ipsilateral, 
objetos colocados na linha média do corpo foram agarrados predominantemente com a mão direita a partir dos 6 meses de idade. Além disso, preensões realizadas com a mão direita demonstraram maior fineza de controle do que quando realizadas com a mão esquerda. Mais recentemente, Rönnqvist e Domellof (2006) avaliaram a preferência manual e assimetria de desempenho motor por análise cinemática na ação de alcançar, comparando bebês com idades variando entre 6 e 36 meses. Os resultados indicaram que enquanto a preferência manual foi bastante inconsistente em idades precoces, a análise cinemática revelou um perfil de desempenho caracterizado por poucas unidades de movimento e movimentos mais retilíneos no alcançar realizado com o braço direito em comparação com o esquerdo. Esse padrão foi observado para a maioria dos bebês em todas as idades avaliadas (ver também Morange-Majoux, Peze, \& Bloch, 2000). Achados de pesquisa adicionais têm mostrado uma vantagem de desempenho na execução com a mão direita em tarefas requisitando altas frequências de movimento em diferentes idades durante a infância (Bruml, 1972; Denckla, 1974; Fagard, 1987; Ingram, 1975) e ações manipulativas (Caplan \& Kinsbourne, 1976; Petrie \& Peters, 1980). Em conjunto, esses resultados têm sido considerados como refletindo uma dominância lateral intrínseca ao sistema de controle de movimentos composto por hemisfério cerebral esquerdo e segmentos corporais do lado direito do corpo.

\section{Fatores Ontogenéticos na Formação da Lateralidade}

A despeito dos resultados de pesquisa apresentados na sessão anterior favorecerem a interpretação de determinação filogenética da lateralidade humana, Provins (1997a, 1997b) questionou este ponto de vista ao apresentar extensa revisão de literatura indicando que assimetrias laterais de desempenho são específicas à tarefa e nem sempre favoráveis à mão direita. Nestes trabalhos, ainda, Provins relata evidências do importante papel de experiências práticas no estabelecimento de assimetrias de desempenho, o que é contrário ao pensamento dominante de que a lateralidade é fundamentalmente determinada por hereditariedade. Serrien, Ivry e Swinnen (2006) têm desenvolvido mais recentemente esta perspectiva ao propor uma visão dinâmica da relação entre os dois lados do corpo, com variação de tal relação sendo determinada em diferentes escalas de tempo. Em curto prazo a lateralidade seria afetada por fatores tais como atenção e contexto (cf. Gabbard \& Helbig, 2004). Em uma escala de tempo mais ampla a aprendizagem desempenharia o papel principal, com o diferencial de prática entre os segmentos de um lado e outro do corpo induzindo preferência lateral (cf. Teixeira \& Teixeira, 2007) e assimetrias interlaterais de desempenho (cf. Teixeira, 2000). Na escala temporal mais ampla, a lateralidade é proposta ser moldada por fatores tais como desenvolvimento motor (cf. P. J. Bryden \& Roy, 2005), envelhecimento (cf. Francis \& Spirduso, 2000) e níveis elevados de proficiência motora (cf. Mikheev, Mohrb, Afanasiev, Landis, $\&$ Thut, 2002). Nesse sentido, a dimensão lateral do comportamento motor é entendida como estando sujeita aos mesmos princípios de desenvolvimento da motricidade em geral, com aperfeiçoamento ocorrendo em função de prática específica com um dado segmento corporal. A partir desse ponto de vista, considerando que há uma pressão social considerável a favor do uso da mão direita (Zverev, 2006), o ambiente poderia desempenhar o papel primário para o estabelecimento da preferência lateral e assimetrias interlaterais de desempenho.

A noção de formação da preferência lateral e de assimetrias interlaterais de desempenho como resultado de interação com o ambiente tem sido sustentada em uma série de estudos. Um estudo abrangente nessa linha foi conduzido em uma investigação populacional no Havaí. Empregando um modelo estatístico de análise de segregação, Ashton (1982) estudou os dados de mais de 1800 famílias havaianas - pais, filhos, e seus ancestrais - sobre suas preferências manuais. Os resultados indicaram que a participação filogenética na determinação da manualidade foi bastante reduzida, ficando em torno de apenas $10-20 \%$, enquanto que componentes ambientais foram apontados como tendo a participação principal. Uma estratégia alternativa de investigação do papel do ambiente na formação da lateralidade consiste em comparar as preferências manuais em diferentes culturas, a fim de observar se a proporção de indivíduos destros e canhotos flutua em função da pressão social para uso da mão direita. Tais estudos têm indicado que, apesar de a preferência manual direita ser predominante na população em geral, observam-se diferenças na incidência de indivíduos destros e canhotos de acordo com a cultura estudada. Comparando crianças indianas e francesas entre 4 e 6 anos de idade, Singh et al. (2001) encontraram preferência manual esquerda em, respectivamente, $3,2 \%$ e $9,6 \%$ das crianças avaliadas. Essa diferença pode ser atribuída a fatores culturais, visto que em determinadas sociedades há uma forte pressão contra o uso da mão esquerda, principalmente para escrever e se alimentar. Em outro estudo com aparente efeito cultural, observou-se que em um grupo de estudantes de escolas coreanas possuindo preferência manual esquerda $59 \%$ foram pressionadas a mudar sua preferência manual. Os resultados indicaram que, dentre elas, $61 \%$ foram convertidas à preferência manual direita após algum tempo (Meng, 2007). Um aspecto especialmente interessante deste estudo foi que a quantidade de crianças canhotas convertidas em destras aumentou em função da série escolar. No jardim de infância a proporção de crianças com modificação da preferência para mão direita foi de $42 \%$, enquanto que entre a quarta e sexta séries este valor atingiu $71 \%$. Parte das crianças que se converteram a destras passaram a preferir a mão direita particularmente para escrever e se alimentar, o que eram os comportamentos mais deseja- 
dos pelos seus cuidadores (ver também Greenwood, Greenwood, McCullagh, Beggs, \& Murphy, 2007; Porac, Coren, \& Searleman, 1986). De forma complementar, têm sido apresentadas evidências de que a consistência de preferência lateral em indivíduos destros é maior em crianças mais velhas e na adolescência do que em fases iniciais da infância (Coren, Porac, \& Duncan, 1981; Leconte \& Fagard, 2006) e maior em idosos em comparação a adultos jovens (Teixeira, 2008). A partir destes resultados, fica aparente que a manualidade é moldada continuamente pelas experiências acumuladas durante o ciclo de vida.

Outra abordagem de investigação que apresentou resultados contraditórios com a proposição de determinação filogenética da lateralidade foi desenvolvida por Jancke e Steinmetz (1995). Nesse estudo 20 pares de gêmeos monozigóticos, dos quais 10 pares possuíam mesma preferência lateral pela mão direita e 10 pares preferências manuais contrárias, foram testados em uma tarefa de toques manuais repetidos com máxima frequência e em outra tarefa envolvendo movimentos de escrita. Essas tarefas foram realizadas com as mãos direita e esquerda. A análise de correlação intraclasse, para as categorias de concordância e discordância de preferência manual, indicou que não houve correlação significativa para a magnitude de assimetria intermanual de desempenho. Esses resultados indicam que mesmo em situações em que o genoma é idêntico entre duas pessoas não há uma vantagem homogênea do lado preferido sobre o lado não-preferido em tarefas manuais. Portanto, a variabilidade de assimetrias intermanuais entre gêmeos monozigóticos indica que este comportamento é determinado por fatores extra-genéticos.

Evidência mais direta do efeito da prática e de experiências sensório-motoras ao longo do processo de desenvolvimento sobre a formação da lateralidade foi obtida em um trabalho em que foram avaliados os casos de três bebês, com histórias singulares de desenvolvimento, durante os dois primeiros anos de vida (Corbetta, Williams, \& Snapp-Childs, 2006). Um deles apresentava lesão no hemisfério cerebral esquerdo, tendo sido submetido a partir dos 6 meses a um programa regular de fisioterapia, com sessões de estimulação sensório-motora aplicadas ao braço direito, a fim de prevenir o esperado quadro de hemiparesia nos meses posteriores. Nos outros dois casos havia padrões individuais e incomuns de locomoção. Um deles desenvolveu uma forma assimétrica de locomoção, através da qual se locomovia arrastando o abdômen e impulsionando o corpo com o braço esquerdo, enquanto mantinha o braço direito livre para alcançar e agarrar objetos ao seu redor. O outro bebê se locomovia movimentando ambos os braços e as pernas simetricamente. Inicialmente, os três bebês apresentavam alcance unimanual com preferência manual esquerda. Entretanto, concomitantemente com o desenvolvimento da locomoção e prática em novas experiências sensóriomotoras, os bebês desenvolveram preferência manual consistente com o padrão de movimento utilizado mais frequentemente. $\mathrm{O}$ bebê que apresentava padrão assimétrico de locomoção desenvolveu preferência manual direita, enquanto que aquele que apresentava padrão simétrico passou a manifestar alcances bimanuais. $\mathrm{O}$ bebê submetido à estimulação sensório-motora do braço direito demonstrou preferência manual direita na avaliação feita aos 8 meses de idade, a qual foi mantida inalterada na replicação da avaliação no segundo ano de vida. Um aspecto a ser destacado nos resultados deste último bebê é que apesar da disfunção no hemisfério cerebral contralateral, o treino com o braço direito no primeiro ano de vida foi efetivo em converter a preferência manual esquerda original em preferência manual direita consistente. Em uma análise geral, esses achados sugerem uma relação entre as mudanças na preferência manual no primeiro ano de vida e a prática em novas experiências, conforme o bebê adquire habilidades sensóriomotoras. Tal interpretação é consistente com a variabilidade da preferência manual observada em bebês normais no primeiro ano de vida (Corbetta \& Thelen, 1999; Gesell \& Ames, 1947; Ramsay, 1980) e conduz à conclusão de que a lateralidade não é uma dimensão comportamental rígida, preestabelecida ao nascimento.

A imitação do comportamento lateralizado de adultos tem sido mostrada ser outro elemento ambiental que afeta o desenvolvimento da lateralidade em bebês. Nagy et al. (2005) observaram o comportamento imitativo em neonatos nas primeiras 3-96 h de vida. Durante este período, foram analisados os movimentos imitativos dos bebês em resposta a movimentos de protrusão do dedo indicador do experimentador. Ao longo de uma série de tentativas houve um decréscimo no tempo de resposta e aumento na acurácia do gesto imitado, demonstrando aprendizagem por imitação. Um resultado interessante, e ao mesmo tempo inesperado, desse estudo foi que os neonatos avaliados demonstraram predominância de uso da mão esquerda durante o gesto imitado. Em um estudo subsequente, Fagard e Lemoine (2006) também observaram que em crianças de 12 a 15 meses de idade a mão usada pelo experimentador para apresentação de um objeto para preensão influenciou a escolha da mão usada pela criança. Inicialmente a maioria das crianças demonstraram preferência manual direita. No entanto, quando o objeto foi apresentado com a mão esquerda nenhuma das crianças manifestou preferência manual direita consistente para manipular o brinquedo. A partir destes resultados, fica aparente que o comportamento imitativo é um dos fatores com potencial para moldar a preferência manual no início do processo de desenvolvimento motor. Evidências adicionais indicam que existe congruência entre a preferência manual do bebê e a preferência manual da mãe, enquanto que o mesmo não tem sido verificado em relação à preferência manual do pai (cf. Ashton, 1982; Harkins \& Michel, 1988). Em famílias com pais discordantes em relação à preferência manual, a descendência manual esquerda provém com maior frequência da mãe 
do que do pai (Annett, 1978, 1999). A influência materna na preferência manual do bebê pode estar relacionada à interação social entre a mãe e o bebê (Harkins \& Uzgiris, 1991), principalmente nos seus primeiros meses de vida, durante o período de amamentação. É possível que, durante essa interação, os bebês utilizem o comportamento imitativo como uma forma de escolher entre uma de suas mãos, imitando aquela usada pela mãe. Como consequência, a manualidade materna poderia ter um efeito decisivo no estabelecimento da preferência manual de seus filhos não por herança genética, mas por simples imitação de movimentos lateralizados.

\section{Uma Proposta Conciliatória}

Uma avaliação global dos resultados de pesquisa relatados nesta revisão não conduz a uma conclusão inequívoca sobre a prevalência de um componente, filo ou ontogenético, no estabelecimento de preferências laterais e assimetrias interlaterais de desempenho. Pelo contrário, os achados aqui apresentados sugerem que há uma combinação complexa de predisposições inatas com experiências sensório-motoras lateralizadas definindo a maneira particular pela qual o comportamento motor de um indivíduo será enviesado à direita ou à esquerda. Essa conclusão, assim, não é consistente com concepções puras de determinação filogenética ou ontogenética da lateralidade humana. Um ponto de vista que parece estar sendo desconsiderado no embate entre tais concepções é que a contribuição genética na formação da lateralidade pode se dar em alguns poucos comportamentos, que influenciam vários outros, ao invés de consistir em uma vantagem global de desempenho de um lado do corpo sobre o outro. Nesse sentido, tendências laterais observadas precocemente no desenvolvimento infantil poderiam representar um importante fator no início do processo de lateralização do comportamento motor de um indivíduo. A partir da noção da lateralidade como um componente dinâmico da motricidade humana, sendo continuamente moldada por eventos ocorrendo em diferentes escalas de tempo (Provins, 1997a, 1997b; Serrien et al., 2006), predisposições inatas de caráter específico corresponderiam ao marco zero de um processo se desenrolando ao longo do ciclo de vida.

Um achado em particular que poderia ser evocado para desenvolver o ponto de vista aqui apresentado é originário do trabalho de Coryell e Michel (1978), com tendência inata de orientação lateral direita nos movimentos da cabeça, e consequente maior frequência de contato visual com a mão direita. Esta observação poderia ser interpretada da seguinte maneira. Por estar mais tempo com a cabeça voltada para o lado direito, o bebê passa a receber mais frequentemente informação sensorial dominante para movimentos voluntários do braço que está dentro de seu campo visual. Como a observação de um segmento corporal em movimento mobiliza recursos atencionais im- portantes para a promoção de plasticidade neural (Conte et al., 2007; Stefan, Wycislo, \& Classen, 2004), esta simples preferência de orientação da cabeça, por si só, teria o potencial de promover assimetrias na estrutura de controle motor. A partir desta tendência comportamental precoce no desenvolvimento motor, o bebê acumula experiências sensoriais e motoras em maior quantidade com o braço que fica mais tempo em seu campo visual em comparação com o braço contralateral. Como o exercício sistemático de ações sensório-motoras promove transformações estruturais e funcionais no sistema nervoso específicas ao hemisfério cerebral mais ativo (Greenough, Larson, \& Withers, 1985; Nudo, Milliken, Jenkins, \& Merzenich, 1996; Ridding \& Flavel, 2006), este fator poderia desencadear assimetrias interlaterais na arquitetura de redes neurais associadas à preferência manual $\mathrm{e}$ assimetrias intermanuais de desempenho. $\mathrm{Na}$ dimensão comportamental, com o uso mais frequente de um dos braços e orientação dos movimentos via feedback visual, o resultado esperado é que o bebê passe em um curto intervalo de tempo a possuir controle mais refinado sobre este braço, por efeito de aprendizagem, em comparação com o braço contrário. A partir de movimentos de alcance mais bem controlados com um dos braços, seria estabelecida então uma preferência lateral baseada em efetiva assimetria da capacidade de controle entre os membros.

Um aspecto de particular relevância no estabelecimento da preferência manual no alcançar é que esta ação precede a execução da maioria de ações manipulativas, nas quais o bebê estende um dos braços em direção a um alvo de preensão para só então agarrar o objeto e manipulá-lo. Dessa forma, a habilidade motora de alcançar pode representar um potente elemento de difusão da preferência manual para as mais diversas ações manipulativas (cf. Hinojosa, Sheu, \& Michel, 2003). Com posterior prática unilateral em habilidades manipulativas, seria estabelecida uma assimetria motora favorável àquele lado do corpo usado mais frequentemente em uma variedade de movimentos voluntários. Com a repetição sistemática de prática lateralizada, a expectativa é de estabelecimento de assimetrias estruturais entre os dois hemisférios cerebrais, resultantes de sinaptogênese cortical (Kleim et al., 2004) e modificação de mapas corticais responsáveis pela somestesia (Pascual-Leone \& Torres, 1993), assim como planejamento e controle daquela ação motora (cf. FloyerLea \& Matthews, 2004; Morgen et al., 2004). A partir desta sequência, portanto, seriam estabelecidas assimetrias interlaterais nas dimensões neural e comportamental em diferentes ações manuais, cuja origem seria uma tendência inata de orientação predominante da cabeça para o lado direito do corpo.

Um caminho alternativo, possivelmente complementar, para disseminação da preferência manual entre diferentes ações motoras foi apresentado recentemente por Teixeira e Okazaki (2007). Nesse estudo foi mostrado que 
a preferência manual direita em indivíduos destros para desempenhar uma tarefa de toques sequenciais entre os dedos de uma das mãos foi modificada após prática com a mão esquerda nesta tarefa. $O$ dado de maior relevância para a presente discussão foi que a preferência predominante pela mão esquerda, estabelecida para a tarefa praticada, foi generalizada para uma tarefa envolvendo uma sequência distinta de toques sequenciais entre os dedos. A partir destes resultados foi evidenciado que a preferência manual pode ser formada em função de prática específica, e que tal preferência é transferida para outras ações motoras de natureza semelhante. Colocando esta noção em uma perspectiva desenvolvimental, a aquisição de preferência manual específica para uma ou mais ações manipulativas pode se revelar como um potente elemento de difusão da preferência manual para as mais diversas tarefas envolvendo o uso de uma das mãos para manipulação. Como consequência, ao longo do tempo seria estabelecida uma preferência generalizada pelo uso de uma das mãos em função de maior confiança ou formação de hábito, em lugar de ser motivada por uma efetiva vantagem de desempenho motor favorável ao braço preferido. Portanto, contrariamente ao que é teorizado por Annett (1978), no modelo conceitual aqui apresentado a preferência manual tem primazia sobre o desenvolvimento da grande maioria das assimetrias de desempenho entre os lados direito e esquerdo do corpo.

Como conclusão da discussão dos resultados de pesquisa e considerações apresentadas no presente trabalho, propomos que a forte preferência lateral e vantagem de desempenho com a mão direita em diversas tarefas motoras em indivíduos destros não é resultante de uma assimetria estrutural global entre os hemisférios cerebrais programada no código genético. Alternativamente, a lateralidade é entendida como um elemento dinâmico da motricidade humana, em que predisposições inatas são reforçadas ou modificadas pela contínua interação com o ambiente durante o ciclo de vida de um indivíduo. Tal interpretação representa uma conciliação entre visões de origem filo e ontogenética da lateralidade humana, com maior potencial de explicar coerentemente os achados de pesquisa disponíveis.

\section{Referências}

Annett, M. (1978). Genetic and nongenetic influences on handedness. Behavior Genetics, 8, 227-249.

Annett, M. (1996). In defense of the right shift theory. Perceptual and Motor Skills, 82, 115-137.

Annett, M. (1999). Left-handedness as a function of sex, maternal versus paternal inheritance, and report bias. Behavior Genetics, 29(2), 103-114.

Ashton, G. C. (1982). Handedness: An alternative hypothesis. Behavior Genetics, 12, 125-147.

Bagesteiro, L. B., \& Sainburg, R. L. (2002). Handedness: Dominant arm advantages in control of limb dynamics. Journal of Neurophysiology, 88, 2408-2421.
Bruml, H. (1972). Age changes in preference and skill measures of handedness. Perceptual and Motor Skills, 34, 3-13.

Bryden, M. P. (1990). Choosing sides: The left and right of the normal brain. Canadian Psychology, 31, 297-309.

Bryden, M. P., Ardila, A., \& Ardila, O. (1993). Handedness in native Amazonians. Neuropsychologia, 31, 301-308.

Bryden, P. J., \& Roy, E. A. (2005). Unimanual performance across the age span. Brain and Cognition, 57, 26-29.

Caplan, P. I., \& Kinsbourne, M. (1976). Baby drops the rattle: Asymmetry of duration of grasp by infants. Child Development, 47, 532-534.

Cioni, G., \& Pellegrinetti, G. (1982). Lateralization of sensory and motor functions in human neonates. Perceptual and Motor Skills, 54, 1151-1158.

Conte, A., Gilio, F., Iezzi, E., Frasca, V., Inghilleri, M., \& Beradelli, A. (2007). Attention influences the excitability of cortical motor areas in healthy humans. Experimental Brain Research, 182, 109-117.

Corbetta, D., \& Thelen, E. (1999). Lateral biases and fluctuations in infants' spontaneous arm movements and reaching. Developmental Psychobiology, 34, 237-255.

Corbetta, D., Williams, J., \& Snapp-Childs, W. (2006). Plasticity in the development of handedness: Evidence from normal development and early asymmetric brain injury. Developmental Psychobiology, 48, 460-471.

Coren, S., Porac, C., \& Duncan, P. (1981). Lateral preference behaviors in preschool children and young adults. Child Development, 52, 443-450.

Coryell, J. (1985). Infant rightward asymmetries predict righthandedness in childhood. Neuropsychologia, 23, 269-271.

Coryell, J. F., \& Michel, G. F. (1978). How supine postural preferences of infants can contribute toward the development of handedness. Infant Behavior and Development, 1, 245-257.

Dahmen, R., \& Fagard, J. (2005). The effect of explicit cultural bias on lateral preferences in Tunisia. Cortex, 41, 805-815.

de Vries, J. I. P., Wimmers, R. H., Ververs, I. A. P., Hopkins, B., Savelsbergh, G. J. P., \& van Geijn, H. P. (2001). Fetal handedness and head position preference: A developmental study. Developmental Psychobiology, 39, 171-178.

Denckla, M. B. (1974). Development of motor co-ordination in normal children. Developmental Medicine and Child Neurology, 16, 720-742.

Dittmar, M. (2002). Functional and postural lateral preferences in humans: Interrelations and life-span age difference. Human Biology, 74, 569-585.

Domellöf, E., Rönnqvist, L., \& Hopkins, R. (2007). Functional asymmetries in the stepping response of the human newborn: A kinematic approach. Experimental Brain Research, 177, 324-335.

Fagard, J. (1987). Does manual asymmetry of high-handers change between six and nine years of age? Human Movement Science, 6, 321-332.

Fagard, J., \& Lemoine, C. (2006). The role of imitation in the stabilization of handedness during infancy. Journal of Integrative Neuroscience, 5(4), 519-533.

Floyer-Lea, A., \& Matthews, P. M. (2004). Changing brain networks for visuomotor control with increased movement automaticity. Journal of Neurophysiology, 92, 2405-2412.

Francis, K. L., \& Spirduso, W. W. (2000). Age differences in the expression of manual asymmetries. Experimental Aging Research, 26, 169-180. 
Gabbard, C., \& Helbig, C. R. (2004). What drives children's limb selection for reaching in hemispace? Experimental Brain Research, 156, 325-332.

Gesell, A., \& Ames, L. B. (1947). The development of handedness. Journal of Genetic Psychology, 70, 155-175.

Goodale, M. A. (1990). Brain asymmetries in the control of reaching. In M. A. Goodale (Ed.), Vision and action (pp. 1432). Amsterdam: North-Holland.

Greenough, W. T., Larson, J. R., \& Withers, G. S. (1985). Effects of unilateral and bilateral training in a reaching task on dendritic branching of neurons in the rat motor-sensory forelimb cortex. Behavioral and Neural Biology, 44, 301314.

Greenwood, J. G., Greenwood, J. J. D., McCullagh, J. F., Beggs, J., \& Murphy, C. A. (2007). A survey of sidedness in Northern Irish schoolchildren: The interaction of sex, age, and task. Laterality, 12, 1-18.

Harkins, D. A., \& Michel, G. F. (1988). Evidence for a maternal effect on infant hand-use preferences. Developmental Psychobiology, 21, 535-541.

Harkins, D. A., \& Uzgiris, I. C. (1991). Hand-use matching between mothers and infants during the first year. Infant Behavior and Development, 14, 289-298.

Hepper, P. G., McCartney, G. R., \& Shannon, E. A. (1998). Lateralised behaviour in the first trimester human foetuses. Neuropsychologia, 36, 531-534.

Hepper, P. G., Wells, D. L., \& Lynch, C. (2005). Prenatal thumb sucking is related to postnatal handedness. Neuropsychologia, 43, 313-315.

Hinojosa, T., Sheu, C. F., \& Michel, G. F. (2003). Infant handuse preferences for grasping objects contributes to the development of a hand-use preference for manipulating objects. Developmental Psychobiology, 43, 328-334.

Ingram, D. (1975). Motor asymmetries in young children. Neuropsychologia, 13, 95-110.

Jancke, L., \& Steinmetz, H. (1995). Hand motor performance and degree of asymmetry in monozygotic twins. Cortex, 31, 779-785

Kleim, J. A., Hogg, T. M., Van den Berg, P. M., Cooper, N. R., Bruneau, R., \& Remple, M. (2004). Cortical synaptogenesis and motor map reorganization occur during late, but not early, phase of motor skill learning. The Journal of Neuroscience, 24, 628-633.

Leconte, P., \& Fagard, J. (2006). Which factors affect hand selection in children's grasping in hemispace? Combined effects of task demand and motor dominance. Brain and Cognition, 60, 88-93.

Levy, J. (1976). A review for a genetic component in the determination of handedness. Behavior Genetics, 6, 429-453.

Liederman, J., \& Kinsbourne, M. (1980). The mechanism of neonatal rightward turning bias: A sensory or motor asymmetry? Infant Behavior and Development, 3, 223-238.

McManus, I. C. (1985). Right and left hand skill: Failure of the right shift theory. British Journal of Psychology, 76, 1-16.

Meng, L. (2007). The rate of handedness conversion and related factors in left-handed children. Laterality, 12, 131-138.

Michel, G. F., \& Harkins, D. A. (1986). Postural and lateral asymmetries in the ontogeny of handedness during infancy. Developmental Psychobiology, 19, 247-258.

Michel, G. F., Ovrut, M. R., \& Harkins, D. A. (1985). Hand-use preference for reaching and object manipulation in 6- through 13-month-old infants. Genetic, Social, and General Monographs, 111, 407-427.
Mikheev, M., Mohrb, C., Afanasiev, S., Landis, T., \& Thut, G. (2002). Motor control and cerebral hemispheric specialization in highly qualified judo wrestlers. Neuropsychologia, 40, 1209-1219.

Morange, F., \& Bloch, H. (1996). Lateralization of the approach movement and the prehension movement in infants from 4 to 7 months. Early Development and Parenting, 5, 81-92.

Morange-Majoux, F., Peze, A., \& Bloch, H. (2000). Organisation of left and right hand movement in a prehension task: A longitudinal study from 20 to 32 weeks. Laterality, 5, 351-362.

Morgen, K., Kadom, N., Sawaki, L., Tessitore, A., Ohayon, J., Frank, J., et al. (2004). Kinematic specificity of cortical reorganization associated with motor training. NeuroImage, $21,1182-1187$.

Nagy, E., Compagne, H., Orvos, H., Pal, A., Molnar, P., Janszky, I., et al. (2005). Index finger movement imitation by human neonates: Motivation, learning, and left-hand preference. Pediatric Research, 58, 749-753.

Nudo, R. J., Milliken, G. W., Jenkins, W. M., \& Merzenich, M. M. (1996). Use-dependent alterations of movement representations in primary motor cortex of adult squirrel monkeys. The Journal of Neuroscience, 16(2), 785-807.

Pascual-Leone, A., \& Torres, F. (1993). Plasticity of the sensorimotor cortex representation of the reading finger in the Braille readers. Brain, 116, 39-52.

Peters, M., \& Petrie, B. F. (1979). Functional asymmetries in the stepping reflex of human neonates. Canadian Journal of Psychology, 33, 198-200.

Petrie, B. F., \& Peters, M. (1980). Handedness: Left/right differences in intensity of grasp response and duration of rattle holding in infants. Infant Behavior and Development, 3, 215 221.

Porac, C., Coren, S., \& Duncan, P. (1980). Life-span age trends in laterality. Journal of Gerontology, 35, 715-721.

Porac, C., Coren, S., \& Searleman, A. (1986). Environmental factors in hand preference formation: Evidence from attempts to switch the preferred hand. Behavior Genetics, 16, 251-261.

Provins, K. A. (1990). Handedness and conformity in a small isolated community. International Journal of Psychology, 25, 343-350.

Provins, K. A. (1997a). Handedness and speech: A critical reappraisal of the role of genetic and environmental factors in the cerebral lateralization of function. Psychological Review, 104, 554-571.

Provins, K. A. (1997b). The specificity of motor skill and manual asymmetry: A review of the evidence and its implications. Journal of Motor Behavior, 29, 183-192.

Ramsay, D. S. (1980). Onset of unimanual handedness in infants. Infant Behavior \& Development, 3, 377-385.

Ridding, M. C., \& Flavel, S. C. (2006). Induction of plasticity in the dominant and non-dominant motor cortices of humans. Experimental Brain Research, 171, 551-557.

Rönnqvist, L., \& Domellöf, E. (2006). Quantitative assessment of right and left reaching movements in infants: A longitudinal study from 6 to 36 months. Developmental Psychobiology, 48, 444-459.

Sainburg, R. L. (2002). Evidence for a dynamic-dominance hypothesis of handedness. Experimental Brain Research, 142, 241-258.

Sainburg, R. L., \& Wang, J. (2002). Interlimb transfer of visuomotor rotations: Independence of direction and final position information. Experimental Brain Research, 145, 437-447. 
Saugstad, L. F. (1998). Cerebral lateralisation and rate of maturation. International Journal of Psychophysiology, 28, 37-62.

Serrien, D. J., Ivry, R. B., \& Swinnen, S. P. (2006). Dynamics of hemispheric specialization and integration in the context of motor control. Nature Neuroscience, 7, 160-167.

Singh, M., Manjary, M., \& Dellatolas, G. (2001). Lateral preferences among Indian school children. Cortex, 37, 231-241.

Stefan, K., Wycislo, M., \& Classen, J. (2004). Modulation of associative human motor cortical plasticity by attention. Journal of Neurophysiology, 92, 66-72.

Strogonova, T. A., Pushina, N. P., Orekhova, E. V., Posikera, I. N., \& Tsetlin, M. M. (2004). Functional brain asymmetry and individual differences in hand preference in early ontogeny. Human Physiology, 30, 14-23.

Teixeira, L. A. (2000). Timing and force components in bilateral transfer of learning. Brain and Cognition, 44, 455-469.

Teixeira, L. A. (2008). Categories of manual asymmetry and their variation with advancing age. Cortex, 44, 707-716.

Teixeira, L. A., \& Okazaki, V. H. A. (2007). Shift of manual preference by lateralized practice generalizes to related motor tasks. Experimental Brain Research, 183, 417-423.

Teixeira, L. A., \& Teixeira, M. C. T. (2007). Shift of manual preference in right-handers following unimanual practice. Brain and Cognition, 65, 238-243.

Wang, J., \& Sainburg, R. L. (2007). The dominant and nondominant arms are specialized for stabilizing different features of task performance. Experimental Brain Research, 178, 565-570.

Yeo, R. A., Gangestad, S. W., \& Daniel, W. F. (1993). Hand preference and developmental instability. Psychobiology, 21, 161-168.

Zverev, Y. P. (2006). Cultural and environmental pressure against left-hand preference in urban and semi-urban Malawi. Brain and Cognition, 60, 295-303. 